\title{
Study on Cultural Interpretation of Dog Type Story in Tibetan Folk Tale
}

\author{
Huajun $\mathrm{Pu}^{1}$ \\ ${ }^{1}$ Sichuan Minzu College, Kangding, Sichuan, 626001 \\ 346591653@163.com
}

KEYWORDS: Folk Tale; Dog; Nature Worship; All One; Good and Evil

\begin{abstract}
Dog as an animal image, it appears in large numbers of Tibetan folk story can be divided into " the Dog Getting Rice Seeds" "Ploughing by Dog", "Dogs and Cats enemies" of three types, from generations of storytelling, we can see Tibetan culture to the original concept of animistic nature worship, human beings and the natural interdependence of all things is one of the values of the inner spiritual core of Tibetan. Meanwhile, the Tibetan ancestors take dog as a close contact with the animals in the story also carries moral instruction, but also reflects the unique concept of good and evil.
\end{abstract}

\section{Introduction}

Dogs not only one of the earliest ancestors of humans domesticated animals, but also an important production and living materials exist, some as ancestor worship and ethnic groups were the protection of God. Dog as an animal in the image spread folk tales from around the world, showing the close and excellent quality dog and human contact. However, due to differences in national culture, the story of the animal's position and image of the narrative is different. Tibetan folk story, the dog's image appeared in large numbers, not only to tell the story as the protagonist in the story of the animals, but also carries important folk memory, has a unique Tibetan culture.

\section{The Folklore Dog Tales in Ganzi Tibetan Autonomous Prefecture}

Productivity is extremely underdeveloped Tibetan primitive society, the dog is an important part of life, it is the owner of the security and protection of livestock, it plays an extremely important role in life. Ganzi Tibetan Autonomous Prefecture spread folk story, the story about the dog has a generally "dog take seed" "Ploughing by Dog", "Dogs and Cats enemies" three types.

\section{A. " Dogs take Valley isotype " Stories}

This type of story there are "flooding the sky", "dog brought barley seed", "A Prince of the early story", "happy dog from grace" and so on. "Flood bullish" about the ancient times, flooding, water wave after day, the sky sprinkled gold empress sprinkle gold back floods, but under the sun has been deserted, only the sun and the moon, the sun and the moon married with humans, but no seeds production, then hit a dog on the ground roll, the dog's tail sticking up just a grain of wheat, so the man had crops. "The dog brought the barley seed" is about the Himalayas or when the mound, the Brahmaputra or creek when food mountains on earth, the people live in plenty good day, even the heavens are the envy of the world Buddha joy happiness but people do not know to cherish, random waste food, the children actually wipe dough, was Bodhisattva punishment recover all the food and seeds on the earth, people no deposit particles, hungry dizziness, an old dog seeing crowds of 
people starve to death every day, determined to seek the Buddha mercy, lifting human disaster, which run day and night, day and night against the heavens cry, finally moved Bodhisattva, to hang barley as an old dog its food, old dog want to eat, endured hunger back barley seed, it was once again eat roasted barley flour, never ever dare to spoil the food. "A prince First Story" tells the story of Prince A First in order to save people, not afraid of difficulties and suffering, even in the case of their own due to the count in the loafers become a dog, still dangling from barley seeds obtained from the hands of loafing Back home, people eat the sweet roasted barley flour, and therefore also their own harvest happy love. "Happy dog from grace" is about the long, long time without food before planting the Tibetan Plateau, the gods to let people suffer hunger and cold, send a dog to the distant world to another in search of food seeds, thousands of experienced dog oct hardships, and finally back to the Tibetan Plateau dangling from barley seeds, from people lived a happy life. The above story, the dog almost human in despair when brought valley species (grain or barley), plays a very important role in the Tibetan Plateau Valley mythical narrative species in order to survive and production of Tibetans made an important contribution .

\section{B. "Ploughing by Dog" Stories}

This type of "story of two brothers" represented about two brothers after his death the separation, the eldest son had divided most of the furniture, cattle and houses, the younger son only a small part of the furniture and dog share . Son lazy, not cows, cattle thin and sick, is not arable land. Son industrious, the dog fed too fat, big, pull plows, to arable land. So the eldest son by pretending dog farmland, killing the dog, and the dog corpse hanging on a tree. Son hold the tree crying, leaves into money, the younger son become rich. Son jealous after learning reasons, but also hold the tree crying, it leaves turn cow dung buried. The story of the "dog" not only brought wealth, but also the concept of the Tibetan people to do good and assist the weak performance in the narrative potential story.

\section{C. "Dogs and Cats Enemies Type "Stories}

As the representative, This type of "dog and cat story" is about a childless old couple's children, because the tail and live a prosperous life, after being greedy furrier tail stolen dogs and cats through hardships back tail . But the cat in order to take credit for an old married couple into the calumny, and took credit for the dog, the cat from eating meat every day, dogs only gnawing on a bone, the dog wags its tail met with the main talent, he saw the cat angrily "bark" whining. Owner of the dog with a rope tied to the front door guards, and lie cat has free run arbitrary jump. Story, not only moral enlightenment fable manner sustenance, but also dogs and cats living habits were answered.

\section{The Unique of Tibetan Culture Reflected by of Dog Type Stories}

\section{A. Animistic Nature Worship}

Engels had "caused by Marx," the article pointed out: "People in their own development, with the support of other entities, but those entities are not high-level entities, not an angel, but a low-level entity, is an animal, thereby producing a animal worship " and many other nations, it is the most primitive nature worship Tibetan religion - Bon faith is." animism "the most concentrated expression, natural objects and natural forces them to live and produce-related emergency deemed to have life, and will be the object of worship of great ability. Qinghai-Tibet Plateau is called roof of the world in the mountain range, harsh natural environment, crop production difficult, the dog can not only protect the faithful for the owner of production from subsistence beast attacks, but also 
to protect the safety of life and property owner, the care of home tranquility. Ali Plateau found ancient rock paintings, the "dog" that is one of the themes appeared in large numbers, many of which are exhibited in the hunting and nomadic era, has become the Tibetan ancestors dog's assistant, and people's lives is closely contact. From "dog to fetch Valley isoform" Ikunori story we can also see that the dog served as an extremely important role in the Tibetan ancestors from nomadic hunting and the transition to the era of the agricultural age, and therefore, has a Tibetan dog feelings of admiration, generations have come to bear in mind the dog's gift through these folklore stories. "For thousands of years, dogs such admiration and affection, giving it immense magical power, to show their adoration and the sacred dog. It has become a custom among ingrained in Tibetans." dog in Tibetan hearts enjoy higher status, are not free to abuse, forbidden to eat dog meat, which has evolved into a loyalty in society, and further development of the alliance to kill a dog, worship the gods as an advocate. Kill a dog, such as "Old Tang • Tubo" on the record of ZAP and minister when the Alliance offerings to mutual loyalty oath means. In Tibetan, the dog and the idea also has the role of the town of evil flooding Chong ancient Tibetan expedition or hold large production activities, should kill a dog, bless peace in the harvest season, buried dog festival world, in order to harvest, from natural disasters damage. In some places, as well as New Year festive dinner please eat dog custom, dog eat, people eat reunion dinner. This is the dog of awe and worship life refraction.

\section{B. The Values of All Things are Integrated}

From the story, we can find the source of folk customs and cultural phenomenon, the Tibetan ancestors dog's respect also reflects the unity of all things Tibetan values, all creatures have a life is equal, people and dogs, and animals are closely linked interdependent relationship. In the "Ploughing by Dog" type story, this should be in the field of farming cattle died because of harsh masters, the main people did not bring wealth, but should guard home dog because the owner's love grow physique It can be like cattle farmland, mainly bring wealth. Therefore, we are recognizing and rational use of dependencies such people and animals can get benefits, on the contrary it was bad luck. "Dogs take Valley isotype" story, but also for people to bring dog food, in terms of human survival and production of significant contribution deserved to worship God as an animal, and human heroes enjoy equal status. "A Prince's First Story", in order to bring mankind into a barley prince dog, the body has changed, but its inner spirit and soul has not changed, so it has been love, unlock the spell and restore personal . Meanwhile, in the Original Belief in human and animal soul sustenance from each other, especially in the human soul can be pinned on various natural objects, such as "Life of King Gesar", the son of God and God protected him Gesar Meanwhile born, their brothers and sisters are animals, there are a white eagle, a red tiger, a green snake, a small female, a nine black snake, a white crow, three iron eagle, a only copper and a black bitch Qinglang. Through the soul sustenance way interdependence between man and the natural world, the values of equality can be achieved, the protection of animals is to protect themselves, so all things are integrated is the intrinsic values of the Tibetan spiritual core.

\section{Bear Moral Instruction}

In Tibetan areas, limiting the geographical environment, economic development, cultural and educational aspects of the subject, folk tales not only an important way civilians spare time entertainment, but also get historical memory, perception of the outside world, the only accepted form of enlightenment. Higher frequency of close contact with people living dog appeared in folk stories, bearing the Group Memory and moral instruction. In the "story of two brothers", the tyrannical brother, sloth, envy, arable land and killed dog was punished, brother kind, hard-working, 
as the family dog, get wealth, therefore, give the owner brought the dog treat Good luck, the dog who will suffer the consequences. Such good and evil has been reported morality extended to life, it is to treat others, treat all creatures around. "Dog and cat story", the dog is extremely loyal to his master, despite suffering after cat calumny, the owner has been misunderstood, but still stubbornly persists, do not blame the heart, obey the master arrangement. Zhongxin is wonderful human quality, the advantage of being mapped out dogs glory of human nature. It also recorded the incident, Tang will and Xu Fan will kilima conferences, white dog had killed for the AU, after the attack at kilima Xu Zhao Hui Cong spell, killing eligible for very heavy. "In dishonesty unhappy, frustrated in the military, Russia moved to Henan Yin, the line to the capital, and Zhao Hui Cong all see the white dog is haunting, with views to die." "New Tang" in the mind come first. Thus, in the concept of Tang, the Tibetan ancestors dog regarded as God, or the protection of God, promises retaliation for Tibetans, so see the white dog is everything, scared to death. Dogs moral instruction of the function in the story

\section{Unique View of Good and Evil}

"The story of two brothers" in spite of what goes around comes around aired morality, but it is worth noting that the story of the punishment of the wicked is extremely severe, evil with violence, with invisible magic power to reach Correctional evil and promote good purpose, punished not only suffered the humiliation of cow dung, but life has to end there, the magic power of this dog is from the gods, in the story, the dog is not only a symbol of wealth, but also punishing evil Yangshan perpetrators. As the two brothers, my brother does not read dependent blood brotherhood, dominating possessions, but also bring wealth to his brother killed the dog in storytellers and audience opinion, indeed too hateful brother's behavior, from brother to death penalty in one respect is a reflection of good and evil folk Jieruchou View, which contains the affirmation of evil, in such a concept, the evil cannot be divisible can not reflect the good and evil cannot be converted into good. In the "dog and cat story", the cat lying obtained master's favor because, delicious good live, free, and loyal dog not only credit was taken away, can only eat the bones, loss of freedom is tied up with iron chains cats and dogs from enemies. We will find a careful analysis, lead to the dog snatched the credit is not the culprit cat lies, but the owner cannot tell right from wrong. But the dog still loyal to the owner, not the slightest blame, and resentment are all the blame on the cat. A reflection of the owner of the dog absolute loyalty, the inextricable link between people in close contact with the dog; the second reflects the era of serfdom Tibetan people, as the existence of a collective unconscious, a slave to the serf owners have absolute obedience and unquestioned nature; three reflects a value judgment of good and evil is a reality-based motives interests, and the interests of the owner of the dog cannot fight, can only snatch interests and cats. Thus, we can see that the Tibetan cultural pluralism tendency internal good and evil, not the full pursuit of perfection, cannot be generalized.

In Tibetan, the dog was supported by widely respected animals, are mostly in a positive image in the folk tale, the representative of the Tibetan faithful pursuit of outstanding character. Tibetan fasting dog, kill a dog but for the AU; do not abuse the dog, let the dog in the suffering of the story; the dogs were as closely linked with people's nature worship of God, given its moral enlightenment narrative function, and let it play the complexity of the evaluation criteria of good and evil, showing the unique Tibetan culture.

\section{Acknowledgements}

Proj: Ministry of Education, Humanities and Social Sciences Fund Project Planning "Kham 
Tibetan Folk Tales Sorting and Research".

Project No. 10YJA751082.

Proj: Sichuan College of Humanities and Social Sciences in General National Project "Cultural

Studies Ganzi Folk Zodiac Story - A Comparison with Ancient Chinese Zodiac Story Literature".

Project No. 12XYZB017.

\section{REFERENCE:}

[1]Snowy Context - Ganzi Tibetan folk songs proverb highlights [M] Beijing; China Federation of Literature Publishing House, 2008.

[2] Marx, Engels, Marx and Engels Collected Works (Volume 27) [M]. Beijing: People's Publishing House, 1972.

[3] Caichang•Gazang Caidan. Observed warehouse [M]. Lhasa: Tibet People's Publishing House, 2006.

[4] Chen Xiezhang. Tibetan Historical Collection (a) [M] Chengdu: Sichuan Ethnic Publishing House, 1982. 